\title{
Grey Relational Analysis for the Production of Dimethyl Ether Syngas in a Biomass Pyrolysis Reactor
}

\author{
Tingzhou Lei ${ }^{1}$, Zhiwei Wang ${ }^{1,2, *}$, Yanhua Sun ${ }^{3}$, Xinguang Shi ${ }^{1,2}$, Xiaofeng $\mathrm{He}^{1,2}$ and \\ Jinling Zhu ${ }^{1,2}$
}

${ }^{1}$ Henan Key Lab of Biomass Energy, Zhengzhou 450008, China

${ }^{2}$ Energy Research Institute Co., Ltd, Henan Academy of Sciences, Zhengzhou 450008, China

${ }^{3}$ Henan Station of China Intellectual Property News, Zhengzhou 450008, China

\begin{abstract}
In this study, dimethyl ether (DME) syngas using a biomass pyrolysis reactor was produced. Gas production parameters, including pyrolysis temperature (PT), pumping frequency (PF) of the root blower, and the feeding rate (FR) of the pyrolysis chain motor, were optimised. The $\mathrm{H}_{2}$ and $\mathrm{CO}$ content of the biomass gas, as well as the $\mathrm{H}_{2}: \mathrm{CO}$ ratio, were examined. The relationship between gas production parameters and the biomass gas content was analysed using grey relational analysis (GRA). The result shown that PT had the greatest effect on $\mathrm{H}_{2}$ and $\mathrm{CO}$ content and the $\mathrm{H}_{2}: \mathrm{CO}$ ratio of the biomass gas. FR was the second most influential parameter, followed by PF. CO content was influenced most by the three parameters. The optimal DME syngas $\mathrm{H}_{2}: \mathrm{CO}$ ratio was approximately 2 , and this ratio was improved using GRA, which increased the $\mathrm{H}_{2}$ and $\mathrm{CO}$ content as well as the $\mathrm{H}_{2}$ :CO ratio during DME synthesis from biomass gas.
\end{abstract}

Keywords: Biomass, pyrolysis reactor, dimethyl ether syngas, grey relational analysis.

\section{INTRODUCTION}

Biomass energy is a renewable energy source that can be transported and used in liquid form. Biomass offers the possibility to produce carbon-neutral fuels and thus plays an important role in the development and utilisation of renewable energy sources [1-3]. The conversion of lignocellulosic biomass, such as residual wood or straw, into synthetic fuels and chemicals is currently being examined using the bio-liquid concept [4]. $\mathrm{CO}_{2}$ emissions from the transportation sector can be reduced by increasing the use of biofuels, especially when the biofuels are produced from lignocellulosic biomass and biofuel crops [5-7]. As an alternative fuel, dimethyl ether (DME) can address energy security, energy conservation, environmental concerns, and the rapid depletion of petroleum reserves [8]. Because of its oxygen content and improved combustion, as well as the lack of carbon-carbon bonds, DME burns cleaner than oil-derived diesel and can be used for domestic applications $[9,10]$.

DME can be produced from biomass syngas in a two-stage fixed bed [11] or using a single-step process [12]. Gasification of forestry and agricultural residues can also be used for DME syngas production [13,14]. DME syngas production can be achieved using lowtemperature gasifiers, nitrogen dilutes gasifiers, steam and oxygen blown circulating fluidised bed gasifiers,

*Address correspondence to this author at the Huayuan Road 29, Zhengzhou, Henan 450008, China; Tel: +86 3716039 9776; Fax: +86 3716572 6337; E-mail: bioenergy@163.com and steam and oxygen blown gasifiers [15-17]. However, few studies have generated syngas directly from biomass gasification. Lv et al. studied syngas production from biomass-derived char, oil, and gas and intended to explore syngas production from direct biomass gasification, which may be more economically viable [18]. At this time, the relationship between gas production parameters and gas content has not been analysed.

In the study, a biomass pyrolysis reactor was designed to produce DME syngas in the absence of oxygen. The experiment indicated that gas production parameters affected the $\mathrm{H}_{2}$ and $\mathrm{CO}$ content, and also observed some inter-influence between different parameters. Although the gas production parameters (pyrolysis temperature (PT), pumping frequency (PF) of the root blower, and the feeding rate $(F R)$ of the pyrolysis chain motor) and the gas composition $\left(\mathrm{H}_{2}\right.$ content, $\mathrm{CO}$ content, and $\mathrm{H}_{2}: \mathrm{CO}$ ratio) are related, quantitative analysis remains difficult. Grey relational analysis (GRA) offers several advantages over traditional regression analysis, including minimal data requirements, simplicity of use, and reasonable projected outcomes [19]. The Grey theory has been applied previously to energy-related studies. Lu et al. [20] used GRA to explore the dynamic characteristics of different factors affecting the transportation system and to evaluate the relative influence of fuel price, gross domestic product, number of motor vehicles, and travel distance. Lee et al. [21] proposed a perspective of multiple objective outputs to evaluate the energy performance of 47 office buildings and then used the 
multiple-attribute decision-making approach of GRA to rank their energy performance. This case study illustrated the effectiveness of GRA. Chang et al. [22] used GRA to investigate how energy-induced $\mathrm{CO}_{2}$ emissions from 34 industries were affected by the production and use of coal, oil, gas, and electricity. Sensitivity and stability tests (seldom discussed in most GRA studies) were conducted to enhance the reliability of the outcomes. In addition, Yuan et al. [23] examined the relationship between China's energy consumption and economic growth. In the present study, GRA was used to investigate the inter-relationships among gas production parameters and gas composition. The purpose of this study was to identify conditions that increase $\mathrm{H}_{2}$ and $\mathrm{CO}$ production and achieve a reasonable $\mathrm{H}_{2}$ :CO ratio, which can allow biomass resources to be used for DME generation.

\section{EXPERIMENTS}

\section{Biomass Pyrolysis Reactor}

DME syngas production using a gasifying device is required for synthesis. Thus, a biomass pyrolysis reactor was designed to produce DME syngas. Pyrolysis is thermal decomposition in the absence of oxygen. Low process temperatures and long vapour residence times favour the production of charcoal, high temperatures and long residence times increase biomass conversion to gas, and moderate temperatures and short vapour residence times are optimal for producing liquids. Figure $\mathbf{1}$ shows a schematic diagram and photographic view of the

a

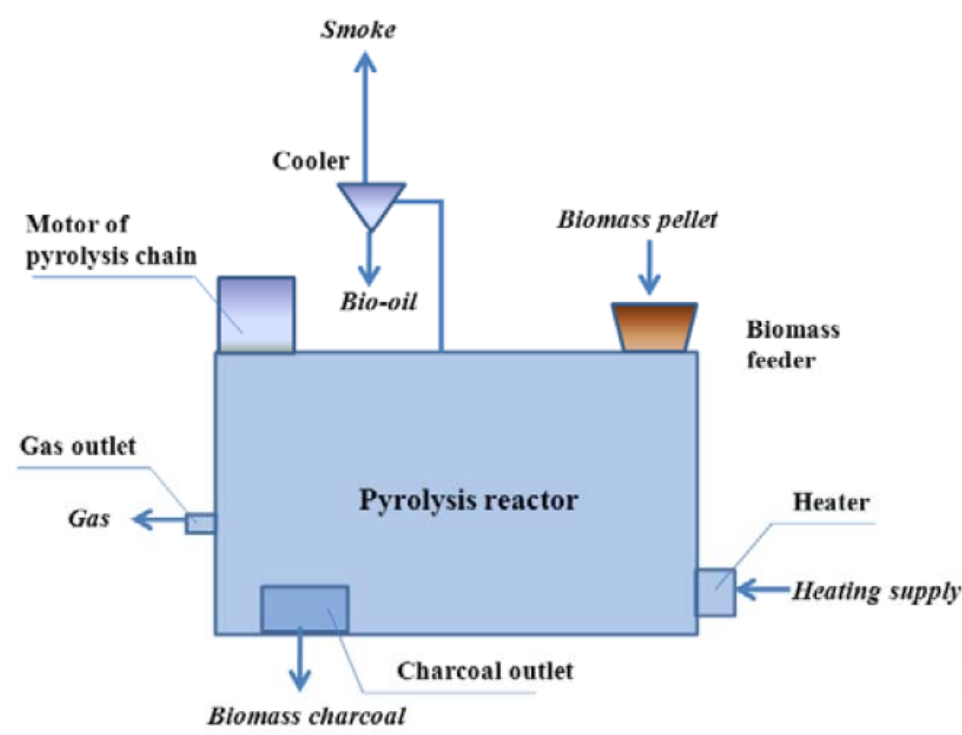

pyrolysis reactor used in this study, which consisted of a biomass feeder, a heater, a charcoal outlet, a motor for the pyrolysis chain, a gas outlet, and a cooler. Biomass pellets entered the pyrolysis reactor via the biomass feeder, and the residence time in the reactor was adjusted by controlling the pyrolysis chain motor. Gas product was drawn out using the root blower, charcoal production was obtained from the charcoal outlet, and bio-oil was obtained from the exhaust smoke after cooling.

The control system of the pyrolysis reactor modulated the PT, PF, and FR to alter the gas content and composition. PT, PF, and FR were the main regulating parameters of the pyrolysis reactor.

\section{Materials}

Corn stalk pellets from a straw fuel plant in Henan province of China were used as biomass fuel for all tests. The average corn stalk pellet diameter and density were $8 \mathrm{~mm}$ and $1.1 \mathrm{t} / \mathrm{m}^{3}$, respectively. Table 1 presents the proximate and final properties and final composition analyses for this pellet fuel. The volatile matter and fixed carbon contents were about $70 \%$ and $18 \%$, respectively. The pellets had low ash and sulphur contents.

\section{PROCEDURE AND TEST RESULTS}

Gas composition from biomass pyrolysis reactor was analysed using two gas chromatograph (GC) apparatuses (GC-9800-TCD-FID, China). Gases analysed by the first $\mathrm{GC}$ were $\mathrm{H}_{2}, \mathrm{O}_{2}, \mathrm{~N}_{2}, \mathrm{CO}, \mathrm{CH}_{4}$, and

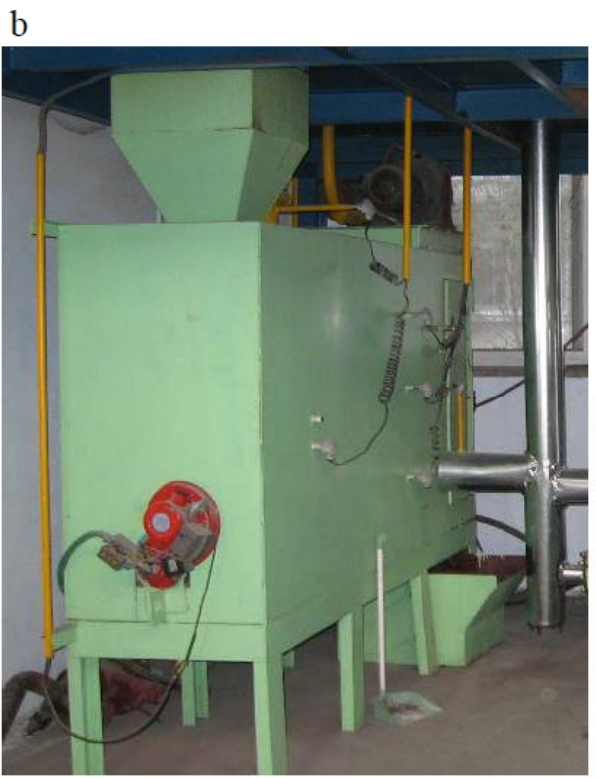

Figure 1: Pyrolysis reactor. (a) Schematic diagram of the reactor and (b) photographic view of the reactor. 
Table 1: Properties and Final Composition Data of Corn Stalk Pellets (Air Dry Basis)

\begin{tabular}{|c|c|c|c|c|c|c|c|c|c|}
\hline \multicolumn{4}{|c|}{ Properties (wt\%) } & \multicolumn{4}{c|}{ Analysis of Final Composition (wt\%) } & \multicolumn{2}{c|}{ LHV (MJ·kg $^{-1}$ ) } \\
\hline V & FC & A & M & C & H & O & N & S & \multirow{2}{*}{16.80} \\
\hline \hline 71.45 & 17.75 & 5.93 & 4.87 & 39.04 & 6.16 & 42.76 & 1.05 & 0.19 & \\
\hline
\end{tabular}

V: volatile; A: ash; FC: fixed carbon; M: moisture.

$\mathrm{CO}_{2}$. The first $\mathrm{GC}$ used a carbon molecular sieve (TDX-01) as a separation column, He as the carrier gas, and a thermal conductivity cell (TCD) detector. Gases analysed by the other $\mathrm{GC}$ were $\mathrm{CH}_{4}, \mathrm{C}_{2} \mathrm{H}_{4}, \mathrm{C}_{2} \mathrm{H}_{6}$ and $\mathrm{C}^{3+}$. The second $\mathrm{GC}$ used a Porapak $\mathrm{Q}(\mathrm{PQ})$ separation column, $\mathrm{N}_{2}$ as the carrier gas, and a flame ionization detector (FID). Post-gasification analyses of the corn stalk pellet and charcoal from the corn stalk pellet were carried out using an automatic ultimate analyser (EA3000, Italy). LHVs for pellets, pellet charcoal, and bio-oil were obtained using a rapid screening device (5E-KCIII, China). Additional analyses of the properties of pellets and pellet charcoal were carried out using an automatic proximate analyser (5EMAC/GIII, China).

Gas from the biomass pyrolysis reactor flowed through a condenser and a root blower, and finally into the gas tank for DME storage or into the gas chromatogram for analysis. The PT and FR in the pyrolysis reactor, cooling rates upon condensation, and the PF of the root blower were all centrally controlled (Figure 2).

Gas production parameters and gas compositions are provided in Table 2.

\section{GREY RELATIONAL ANALYSIS}

\section{Methodology}

The purpose of GRA is to explore the qualitative and quantitative relationships among abstract and complex sequences, to capture their dynamic characteristics during the development process, and to measure the relative influence of the compared series on the reference series $[24,25]$.

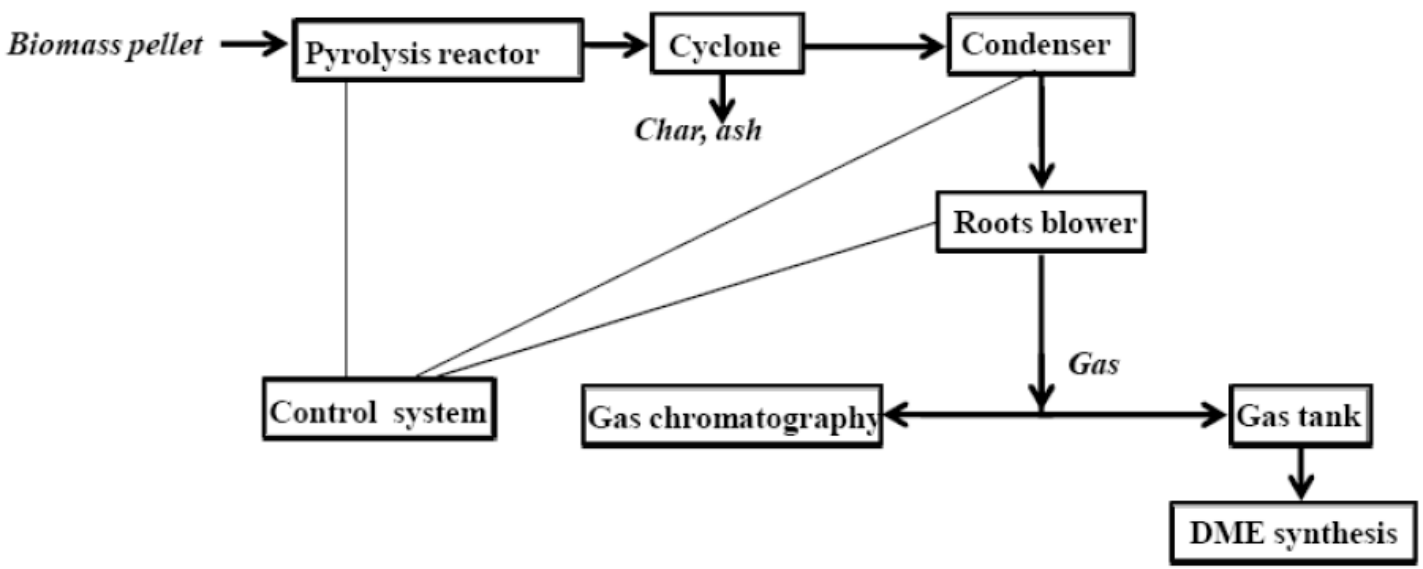

Figure 2: Schematic diagram of the biomass pyrolysis reactor and subsidiary facilities.

Table 2: Gas Production Parameters and Content under Different Conditions

\begin{tabular}{|c|c|c|c|c|c|c|c|c|c|}
\hline & & \multicolumn{8}{|c|}{ Number of test } \\
\hline & & 1 & 2 & 3 & 4 & 5 & 6 & 7 & 8 \\
\hline \multirow{3}{*}{$\begin{array}{c}\text { Gas } \\
\text { production } \\
\text { parameters }\end{array}$} & $\mathrm{PT}\left({ }^{\circ} \mathrm{C}\right)$ & 382 & 423 & 395 & 460 & 511 & 505 & 476 & 492 \\
\hline & $\mathrm{PF}(\mathrm{Hz})$ & 5.0 & 5.9 & 5.3 & 5.8 & 6.0 & 7.7 & 7.0 & 5.5 \\
\hline & $\mathrm{FR}\left(\mathrm{r} \cdot \mathrm{min}^{-1}\right)$ & 100 & 150 & 180 & 120 & 300 & 270 & 320 & 230 \\
\hline \multirow{3}{*}{ Gas content } & $\mathrm{H}_{2}$ (vol. \%) & 23.20 & 34.06 & 31.22 & 35.89 & 36.31 & 33.65 & 30.18 & 32.37 \\
\hline & $\mathrm{CO}$ (vol. \%) & 19.63 & 25.38 & 22.10 & 26.52 & 25.81 & 25.76 & 24.23 & 26.01 \\
\hline & $\mathrm{H}_{2}: \mathrm{CO}$ & 1.182 & 1.342 & 1.413 & 1.353 & 1.407 & 1.306 & 1.246 & 1.245 \\
\hline
\end{tabular}




\section{(1) Standardized treatment}

Assume that $X_{0}=\left\{x_{0}(k), k=1,2, \ldots, n\right\}$ is the sequence of parameters, $X_{j}=\left\{x_{j}(k), k=1,2, \ldots, n\right\}(j=$ $1,2, \ldots, m)$ is the sequence of sub-parameters, $n$ is the length of the sequence, i.e., the number of data points, and $m$ is the number of sub-parameters. The dimensions and units of the original statistical data index are different; thus, the original data shall be subject to a dimensionless standardized treatment. The standardized treatment involves the use of an initial value, a mean, and a regional value. The regional value used in this paper is defined as follows:

$x_{j}^{\prime}(k)=\frac{x_{j}(k)-\min \left[x_{j}(k)\right]}{\max \left[x_{j}(k)\right]-\min \left[x_{j}(k)\right]}$

(2) Calculation of the relational coefficient

The Grey relational coefficient is defined as the following:

$\xi_{0 j}(k)=\frac{\min _{j} \min _{k}\left|x_{0}^{\prime}(k)-x_{j}^{\prime}(k)\right|+\rho \max _{j} \max _{k}\left|x_{0}^{\prime}(k)-x_{j}^{\prime}(k)\right|}{\left|x_{0}^{\prime}(k)-x_{j}^{\prime}(k)\right|+\rho \max _{j} \max _{k}\left|x_{0}^{\prime}(k)-x_{j}^{\prime}(k)\right|}$

For the identification coefficient, $\rho \in[0,1] ; \rho=0.5$ is commonly used.

(3) Calculation of the relational degree

The relational degree indicates the relational between two sequences, or the mean value of the relational coefficients. The relational degree $\left(r_{0 j}\right)$ between the sub-sequence $(j)$ and sequence $(0)$ is:

$r_{0 j}=\frac{1}{n} \sum_{k=1}^{n} \xi_{0 j}(k)$

(4) Sequencing of the relational degree
Arrange the relational degrees of $m$ sub-sequences in the same sequence, to compose the relational order and reflect the relational degree of each sub-sequence to sequence. If there are $t$ sequences $\left\{Y_{1}\right\},\left\{Y_{2}\right\}, \ldots,\left\{Y_{t}\right\}$ $(t \neq 1)$ and $m$ sub-sequences $\left\{X_{1}\right\},\left\{X_{2}\right\}, \ldots,\left\{X_{m}\right\}(m \neq$ $1)$, then the relational degree of each sub-sequence to sequence $\left\{Y_{1}\right\}$ is $\left[r_{11}, r_{12}, \ldots, r_{1 m}\right]$, and the relational degree of each sub-sequence to sequence $\left\{Y_{t}\right\}$ is $\left[r_{t 1}\right.$, $\left.r_{t 2}, \ldots, r_{t m}\right]$, in which $(i=1,2, \ldots, t ; j=1,2, \ldots, m)$. The resulting relational degree matrix, $R$, is given below:

$$
R=\left(r_{i j}\right)=\left[\begin{array}{cccc}
r_{11} & r_{12} & \ldots & r_{1 m} \\
r_{21} & r_{22} & \ldots & r_{2 m} \\
\ldots & \ldots & \ldots & \ldots \\
r_{t 1} & r_{t 2} & \ldots & r_{t m}
\end{array}\right]
$$

In the Grey relational matrix, the elements in row $i$ are the Grey relational degrees of sequence $\left(Y_{i}\right)$ to each sub-sequence $\left\{X_{1}\right\},\left\{X_{2}\right\}, \ldots,\left\{X_{m}\right\}$; the elements in line $j$ are the Grey relational degrees of each sequence $\left\{Y_{1}\right\},\left\{Y_{2}\right\}, \ldots,\left\{Y_{t}\right\}$ to sub-parameter $\left\{X_{j}\right\}$. If every element in one line of $R$ is higher than that in other lines, then the sub-parameter in this line is the superior sub-parameter. If every element in one row of $R$ is higher than that in other rows, then the parameter in this row is the superior parameter.

\section{Relational Analysis}

The gas production parameters and content (Table 2) after the standardised treatment according to Eq. (1) are listed in Table 3.

According to Table 3 and Eq. (2), the number of tests was used as the $x$-coordinate, and the grey relational coefficient was used as the $y$-coordinate. Calculation of the grey relational coefficients of each sequence to each sub-sequence is shown in Figures 3 5.

Table 3: Gas Production Parameters and Content after Data Standardisation

\begin{tabular}{|c|c|c|c|c|c|c|c|c|c|}
\hline \multicolumn{2}{|c}{ Relational sequences } & \multicolumn{9}{c|}{ Number of test } \\
\cline { 3 - 10 } & & $\mathbf{1}$ & $\mathbf{2}$ & $\mathbf{3}$ & $\mathbf{4}$ & $\mathbf{5}$ & $\mathbf{6}$ & $\mathbf{7}$ & $\mathbf{8}$ \\
\hline \hline \multirow{3}{*}{$\begin{array}{c}\text { Gas production } \\
\text { Parameters }\end{array}$} & $\mathrm{X}_{1}$ & 0 & 0.3178 & 0.1008 & 0.6047 & 1.0000 & 0.9535 & 0.7287 & 0.8527 \\
\cline { 2 - 11 } & $\mathrm{X}_{2}$ & 0 & 0.3333 & 0.1111 & 0.2963 & 0.3704 & 1.0000 & 0.7407 & 0.1852 \\
\cline { 2 - 11 } & $\mathrm{X}_{3}$ & 0 & 0.2273 & 0.3636 & 0.0909 & 0.9091 & 0.7727 & 1.0000 & 0.5909 \\
\hline \multirow{3}{*}{ Gas content } & $\mathrm{Y}_{1}$ & 0 & 0.8284 & 0.6117 & 0.9680 & 1.0000 & 0.7971 & 0.5324 & 0.6995 \\
\cline { 2 - 11 } & $\mathrm{Y}_{2}$ & 0 & 0.8345 & 0.3585 & 1.0000 & 0.8970 & 0.8897 & 0.6676 & 0.9260 \\
\cline { 2 - 10 } & $\mathrm{Y}_{3}$ & 0 & 0.6926 & 1.0000 & 0.7403 & 0.9740 & 0.5368 & 0.2771 & 0.2727 \\
\hline
\end{tabular}




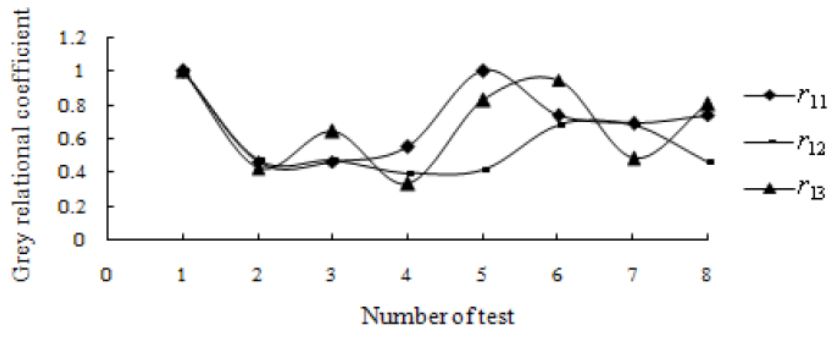

Figure 3: Grey relational coefficient of $Y_{1}$ and $X_{1}, X_{2}, X_{3}$.

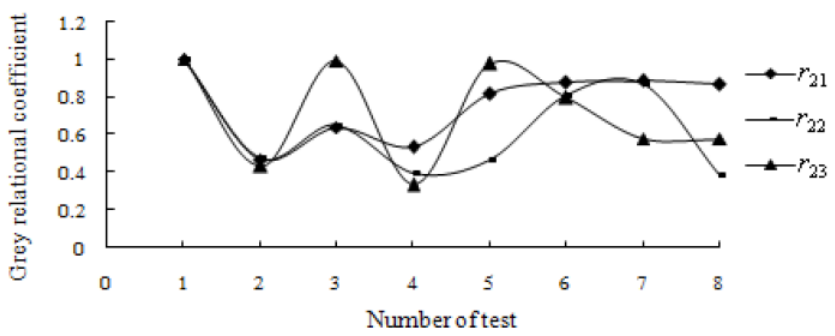

Figure 4: Grey relational coefficient of $Y_{2}$ and $X_{1}, X_{2}, X_{3}$.

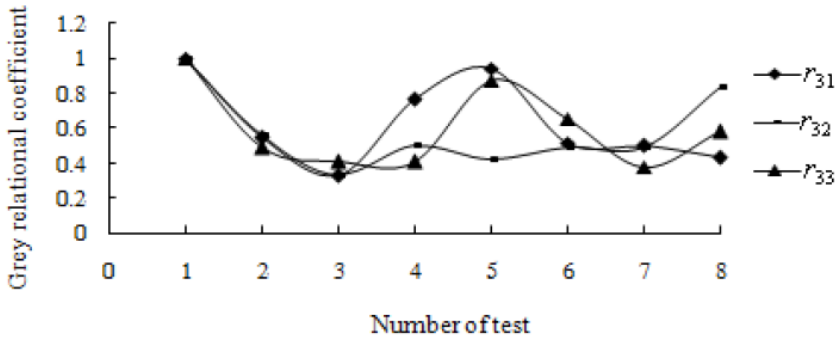

Figure 5: Grey relational coefficient of $\mathrm{Y}_{3}$ and $\mathrm{X}_{1}, \mathrm{X}_{2}, \mathrm{X}_{3}$.

Based on Figures 3-5, the relational degree between the sequence and the sub-sequence can be obtained based on the area formed by each relational coefficient and $x$-coordinate. However, the relational degree was not obvious and requires further investigation.

According to Eq. (3) and (4) and the above calculated data (Table 3 ), the relational degree of gas production parameters to gas content is as follows:

The relational degree of each gas production parameter to gas content $\left\{Y_{1}\right\}$ was $\left[r_{11}, r_{12}, r_{13}\right]=[0.705$, $0.571,0.682]$, where $r_{11}>r_{13}>r_{12} \quad\left(r_{1 j}, j=1,2,3\right.$, representing the relational degree of each gas production parameter to $\mathrm{H}_{2}$ content. $r_{11}$ shows the influence of $\mathrm{PT}$ on $\mathrm{H}_{2}$ content, $r_{12}$ shows the influence of $\mathrm{PF}$ on $\mathrm{H}_{2}$ content, $r_{13}$ shows the influence of $\mathrm{FR}$ on $\mathrm{H}_{2}$ content.), which shows that the influence of PT on $\mathrm{H}_{2}$ content was the most significant.

The relational degree of each gas production parameter to gas content $\left\{Y_{2}\right\}$ was $\left[r_{21}, r_{22}, r_{23}\right]=[0.760$,
$0.628,0.709]$, where $r_{21}>r_{23}>r_{22} \quad\left(r_{2 j}, j=1,2,3\right.$, representing the relational degree of each gas production parameter to $\mathrm{CO}$ content. $r_{21}$ shows the influence of PT on CO content, $r_{22}$ shows the influence of PF on CO content, $r_{23}$ shows the influence of FR on $\mathrm{CO}$ content.), which shows that the influence of PT on CO content was the most significant.

The relational degree of each gas production parameter to gas content $\left\{Y_{3}\right\}$ was $\left[r_{31}, r_{32}, r_{33}\right]=[0.641$, $0.585,0.600]$, where $r_{31}>r_{33}>r_{32} \quad\left(r_{3 j}, j=1,2,3\right.$, representing the relational degree of each gas production parameter to ratio of $\mathrm{H}_{2}: \mathrm{CO}$. $r_{31}$ shows the influence of $\mathrm{PT}$ on $\mathrm{H}_{2}$ :CO ratio, $r_{32}$ shows the influence of $\mathrm{PF}$ on $\mathrm{H}_{2}$ :CO ratio, $r_{33}$ shows the influence of $\mathrm{FR}$ on $\mathrm{H}_{2}$ :CO ratio.), which shows that the influence of $\mathrm{PT}$ on $\mathrm{H}_{2}: \mathrm{CO}$ ratio was the most significant.

The completed relational degree matrix, $R$, is given below:

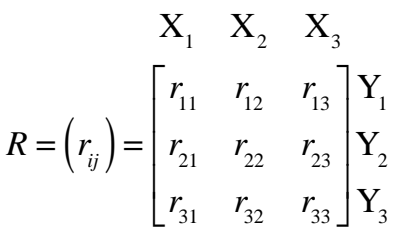

$$
\begin{aligned}
& =\left[\begin{array}{lll}
0.705 & 0.571 & 0.682 \\
0.760 & 0.628 & 0.709 \\
0.641 & 0.585 & 0.600
\end{array}\right]
\end{aligned}
$$

Based on the above analysis and the relational matrix $R$, we determined the following:

The relational degree value of $X_{1}$ was highest; every element of $\mathrm{X}_{1}$ in the relational matrix $R$ was higher than the element in any other line, with a relational degree of $[0.705,0.760,0.641]$. Thus, the sub-parameter in this line was the superior sub-parameter, i.e., the influence of PT on the gas content was most significant. ( $X_{1}$ shows the influence of $\mathrm{PT}$ on the three gas content, $X_{2}$ shows the influence of PF on the three gas content, $X_{3}$ shows the influence of $F R$ on the three gas content).

The relational degree value of $Y_{2}$ was highest; every element of $Y_{2}$ in the relational matrix $R$ was higher than that in any other row, with a relational degree of $[0.760$, $0.628,0.709]^{\top}$. Thus, the parameter in this line was the superior parameter, i.e., the influence of the three parameters on the change in $\mathrm{CO}$ content was the most significant. $\left(Y_{1}\right.$ shows the influence of the three parameters on the change in $\mathrm{H}_{2}$ content, $\mathrm{Y}_{2}$ shows the influence of the three parameters on the change in $\mathrm{CO}$ 
content, $Y_{3}$ shows the influence of the three parameters on the change in $\mathrm{H}_{2}$ :CO ratio.)

The pyrolysis test in this study was mainly prepared for DME synthesis, and the optimal ratio of $\mathrm{H}_{2}: \mathrm{CO}$ in the syngas was 2 . Based on Figure 6 , the ratio of $\mathrm{H}_{2}: \mathrm{CO}$ varied with changes in the test conditions, and its ratio was often lower than 2 . Therefore, DME synthesis was improved by increasing the ratio of $\mathrm{H}_{2}: \mathrm{CO}$. Taking the four highest ratios of $\mathrm{H}_{2}: \mathrm{CO}$, the average values of $\mathrm{PT}, \mathrm{PF}$ and $\mathrm{FR}$ were $447.25^{\circ} \mathrm{C}, 5.57$ $\mathrm{Hz}$, and $187.5 \mathrm{r} \cdot \mathrm{min}^{-1}$, respectively. Based on the above GRA, the influence of $\mathrm{PT}$ on the $\mathrm{H}_{2}: \mathrm{CO}$ ratio varied. Therefore, optimal $\mathrm{PF}$ and $\mathrm{FR}$ values were considered to be $5.57 \mathrm{~Hz}$ and $187.5 \mathrm{r} \cdot \mathrm{min}^{-1}$, respectively. The highest $\mathrm{H}_{2}: \mathrm{CO}$ ratio can be found by adjusting $\mathrm{PT}$ to approximately $447.25^{\circ} \mathrm{C}$.

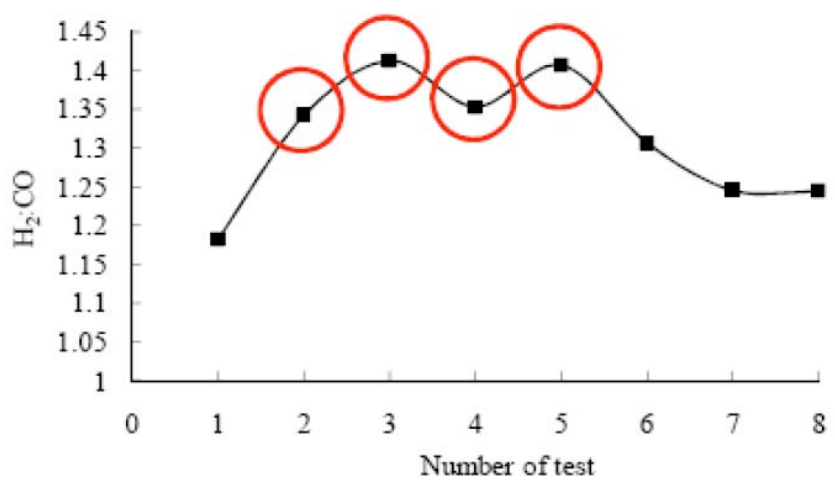

Figure 6: Ratio of $\mathrm{H}_{2}: \mathrm{CO}$ under different test conditions.

\section{CONCLUSIONS}

Based on the pyrolysis tests, three major parameters were adjusted, and the relational data between the adjustable parameters and the $\mathrm{H}_{2}$ and $\mathrm{CO}$ contents were obtained for the biomass pyrolysis reactor. The relationship between the three major parameters and the $\mathrm{H}_{2}$ and $\mathrm{CO}$ contents and ratio of $\mathrm{H}_{2}$ : $\mathrm{CO}$ was analysed by GRA. Based on the results, the following conclusions were made:

(1) PT had the strongest effect on $\mathrm{H}_{2}$ and $\mathrm{CO}$ contents and the $\mathrm{H}_{2}$ : $\mathrm{CO}$ ratio produced by the biomass pyrolysis reactor, and the relational degree of pyrolysis temperature to gas composition was $[0.705,0.760,0.641]$. FR was the secondary influencing parameter, while PF had the weakest effect. The influence of the three parameters on changes in $\mathrm{CO}$ content was the most significant, and the relational degree of CO content to the three parameters was $[0.760$, $0.628,0.709]^{\top}$. When producing DME syngas from the biomass pyrolysis reactor, it is necessary to study the influence of PT on gas production and perform the related pyrolysis test. Temperature played an important role in the pyrolysis reactor, and the gas composition was influenced directly by the PT.

(2) To produce DME syngas with an $\mathrm{H}_{2}: \mathrm{CO}$ ratio close to 2 , the mean value of better parameters among the test data were calculated. Optimal PF and FR values were $5.57 \mathrm{~Hz}$ and $187.5 \mathrm{r} \cdot \mathrm{min}^{-1}$, respectively. The point with the highest $\mathrm{H}_{2}: \mathrm{CO}$ ratio could be found by adjusting PT.

(3) The analysis of gas production parameters and the gas composition to produce DME syngas in biomass gasification tests using the GRA method differed from a pyrolysis dynamics analysis. Our results suggested that GRA could be used to supplement the latter, increasing the comprehensiveness of biomass pyrolysis, and identify preconditions for the production of DME syngas with higher $\mathrm{H}_{2}$ and $\mathrm{CO}$ contents and a suitable $\mathrm{H}_{2}: \mathrm{CO}$ ratio.

\section{ACKNOWLEDGEMENT}

The present investigations have been funded by the Cooperation of Chinese Academy of Sciences and Chinese Province (DBHF-2011-116) and the National Science and Technology Support Program (2012BAD30B03).

\section{REFERENCES}

[1] Wu CZ, Ma LL. Modern utilization technology of biomass energy. Beijing: Chemical Industry Press 2005; pp.1-5.

[2] Tijmensen MJA, Faaij APC, Hamelinck CN, Van-Hardeveld MRM. Exploration of the possibilities for production of Fischer-Tropsch liquids and power via biomass gasification. Biomass Bioenergy 2002; 23: 129-52. http://dx.doi.org/10.1016/S0961-9534(02)00037-5

[3] Chang J, Fu Y, Luo ZY. Experimental study for dimethy ether production from biomass gasification and simulation on dimethyl ether production. Biomass Bioenergy 2012; 39: 6772

http://dx.doi.org/10.1016/j.biombioe.2011.01.044

[4] Trippe F, Fröhling M, Schultmann F, Stahl R, Henrich E, Dalai A. Comprehensive techno-economic assessment of dimethyl ether (DME) synthesis and Fischer-Tropsch synthesis as alternative process steps within biomass-toliquid production. 2012; 9 .

http://dx.doi.org/10.1016/j.fuproc.2012.09.029

[5] Clausen LR, Elmegaard B, Ahrenfeldt J, Henriksen U. Thermodynamic analysis of small-scale dimethyl ether (DME) and methanol plants based on the efficient two-stage gasifier. Energy 2011; 36: 5805-14. http://dx.doi.org/10.1016/j.energy.2011.08.047

[6] Higo M, Dowaki K. A Life Cycle Analysis on a Bio-DME production system considering the species of biomass 
feedstock in Japan and Papua New Guinea. Appl Energy 2010; 87: 58-67.

http://dx.doi.org/10.1016/j.apenergy.2009.08.030

[7] Bonin C, Lal R. Physical Properties of an Alfisol Under Biofuel Crops in Ohio. J Technol Innovations Renewable Energy 2012; 1: 1-13.

[8] Semelsberger TA, Borup RL, Greene HL. Dimethyl ether (DME) as an alternative fuel. J Power Sources 2006; 156: 497-11.

http://dx.doi.org/10.1016/j.jpowsour.2005.05.082

[9] Swain PK, Das LM, Naik SN. Biomass to liquid: A prospective challenge to research and development in 21st century. Renewable Sustainable Energy Rev 2011; 15: 491733.

http://dx.doi.org/10.1016/j.rser.2011.07.061

[10] Marchionna M, Patrini R, Sanfilippo D, Migliavacca G. Fundamental investigations on di-methyl ether (DME) as LPG substitute or make-up for domestic uses. Fuel Process Technol 2009; 89: 1255-61.

http://dx.doi.org/10.1016/j.fuproc.2008.07.013

[11] Lv YX, Wang TJ, Wu CZ, Ma LL, Zhou Y. Scale study of direct synthesis of dimethyl ether from biomass synthesis gas. Biotechnol Adv 2009; 27: 551-4.

http://dx.doi.org/10.1016/j.biotechadv.2009.04.005

[12] Ju FD, Chen HP, Ding XJ, Yang HP, Wang XH, Zhang SH, et al. Process simulation of single-step dimethyl ether production via biomass gasification. Biotechnol Adv 2009; 27: 599-605.

http://dx.doi.org/10.1016/j.biotechadv.2009.04.015

[13] Sarkar S, Kumar A, Sultana A. Biofuels and biochemicals production from forest biomass in Western Canada. Energy 2011; 36: 6251-62. http://dx.doi.org/10.1016/j.energy.2011.07.024

[14] Srirangan K, Akawi L, Moo-Young M, Chou CP. Towards sustainable production of clean energy carriers from biomass resources. Appl Energy 2012; 100: 172-86.

http://dx.doi.org/10.1016/j.apenergy.2012.05.012

[15] Van Rens GLMA, Huisman GH, De Lathouder $H$, Cornelissen RL. Cornelissen Performance and exergy analysis of biomass-to-fuel plants producing methanol, dimethylether or hydrogen. Biomass Bioenergy 2011; 35: 145-54.

http://dx.doi.org/10.1016/j.biombioe.2011.05.020
[16] Huisman GH, Van Rens GLMA, De Lathouder $H$, Cornelissen RL. Cost estimation of biomass-to-fuel plants producing methanol, dimethylether or hydrogen. Biomass Bioenergy 2011; 35: 155-66.

http://dx.doi.org/10.1016/j.biombioe.2011.04.038

[17] Zhang WN. Automotive fuels from biomass via gasification. Fuel Process Technol 2010; 91: 866-76.

http://dx.doi.org/10.1016/j.fuproc.2009.07.010

[18] Lv PM, Yuan ZH, Wu CZ, Ma LL, Chen Y, Tsubaki N. Biosyngas production from biomass catalytic gasification. Energy Conver Manag 2007; 48: 1132-9. http://dx.doi.org/10.1016/j.enconman.2006.10.014

[19] Lin SJ, Lu IJ, Lewis C. Grey relation performance correlations amongeconomics, energy use and carbon dioxide emission in Taiwan. Energy Policy 2007; 35: 194855.

http://dx.doi.org/10.1016/j.enpol.2006.06.012

[20] Lin SJ, Lu IJ, Lewis C. Grey relation analysis of motor vehicular energy consumption in Taiwan. Energy Policy 2008; 36: 2556-61. http://dx.doi.org/10.1016/j.enpol.2008.03.015

[21] Lee WS, Lin YC. Evaluating and ranking energy performance of office buildings using Greyrelational analysis. Energy 2011; 36: 2551-6.

http://dx.doi.org/10.1016/j.energy.2011.01.049

[22] Chang TC, Lin SJ. Grey relation analysis of carbondioxide emissions from industrial production and energy uses in Taiwan. J Environ Manage 1999; 56: 247-57. http://dx.doi.org/10.1006/jema.1999.0288

[23] Yuan CQ, Liu SF, Fang ZG, Xie NM. The relation between Chinese economic development and energy consumption in the different periods. Energy Policy 2010; 38: 5189-98. http://dx.doi.org/10.1016/j.enpol.2010.05.004

[24] Deng JL. Basic method of grey system theory. Wuhan: Huazhong University of Science and Technology Press 1996; pp.19-41.

[25] Zhou XW. The Study on the grey relational degree and its application. PhD Dissertation. Jinlin: Changchun University 2007. 